\title{
Public Policy Frameworks in Environmental Settings: An Argument for New Policy Frameworks to Support New Policy Directions
}

\author{
Chad McGuire (Corresponding author) \\ Department of Public Policy, University of Massachusetts, Dartmouth \\ 285 Old Westport Road, Dartmouth, Massachusetts 02747, United States \\ Tel: 1-508-999-8520_E-mail: cmcguire@umassd.edu
}

Received: March 21, 2012 Accepted: April 11, 2012 Online Published: April 20, 2012

doi:10.5296/emsd.v1i1.1537～URL: http://dx.doi.org/10.5296/emsd.v1i1.1537

\begin{abstract}
Environmental policy is about solving problems, not creating them. Policy frameworks are meant to be supportive of policy initiatives. Most environmental initiatives are impacted by new information, and as such, policy frameworks should be responsive to new information. Often existing policy frameworks limit the ability of information that suggests a change in policy direction. This article discusses some of the causes for this phenomenon and suggests that new policy frameworks should be considered in supporting new policy directions, rather than relying on the manipulation of existing policy frameworks.
\end{abstract}

Keywords: Environmental Policy, Science, Public Policy, Policy Frameworks 


\section{Introduction}

Don't throw the baby out with the bathwater! Many can relate to this idiom that suggests we keep the good in things as we try to work on the bad. This kind of philosophy is often applied to policy settings, and often represented in incremental forms of change to policy frameworks; when there is a problem, like cancer, we try to remove only the piece we believe is causing the problem keeping the reminder intact. For scientists incremental policy adjustments may make sense because the process is not dissimilar to the scientific method itself; a body of preexisting knowledge forms the foundation from which incremental advancements are made. Sometimes new insights cause substantial change in directions of scientific inquiry, but rarely do these insights call for the dismissal of the entire preexisting foundational knowledge.

The purpose of this article is to identify, and in fact recommend, that is it often better to approach policy questions by building entirely new frameworks, or by abandoning existing frameworks as the case may be. The reasons for this recommendation are outlined below, but they all follow a general premise that environmental problems are often impacted by rapidly evolving scientific discoveries. Policy is most useful when it is capable of directly responding to these changes. Existing policy structures can often inhibit the meaningful internalization of new information for a variety of reasons. For example, existing structures might have been developed without consideration for the kinds of scientific discoveries or rates of discovery occurring today. Also, existing structures create a kind of 'institutional knowledge' amongst participants in the particular policy field that may incentivize certain actors to limit the internalization of new information if and when they determine the information to be disadvantageous to their respective interests. Often new policy frameworks that are developed around new information can offer a superior means of addressing the current issue allowing policy to better adapt to available solutions to the problem.

I propose discourse in environmental policy applications currently in force take on the incremental nature of policy development; the policies tend to keep previous versions of a policy in existence, preferring to 'amend' or add-on new parts to the previous policy over time (Lindblom, 1959; Birkland, 2010). I further propose current policy instruments can benefit from thinking outside any traditional paradigms created by previous policy directions. In essence, I am suggesting sound policy instruments can be designed anew without being bound to what might considered prior incarnations of policy directions within the same field. Environmental problems are benefitting from a strong advancement in the earth and natural sciences. This new information should become the fodder from which policy instruments are designed, not something that must dogmatically be retrofitted into a previous policy instrument that may have developed bad habits towards the consideration of new information.

To advance the points being made above, this article will provide the following: first a summary overview of several ways in which policies are believed to be altered will be summarized; special application will be made to environmental policies where appropriate. Second, some examples where a willingness to redesign policy instruments in light of new information will be described in some detail. These examples will highlight the value to be found in providing a wholly new 'design' to policy directions, rather than adhering to 
previous policy directions. Indeed, purposeful design can offer some insight into how we choose to approach problems within our human-bounded framework, allowing us to adopt policy frameworks that move us towards policy instruments resulting in a more directed advancement of our social goals.

\section{Policy Evolution}

Policy study tries to decipher, in varying degrees, the expressions of public choice, the reasons for those choices, and the impacts of those choices (Birkland, 2010). While there is no absolute structural method applied to studying policy creation and development, a variety of frameworks exist that help to create understanding about how public policy evolves. Included in these frameworks are theories about how best to start policy initiatives, and also how best to change existing policy. The focus applied here is on the methods used to change existing policy.

As a starting point, we can assume that existing policies were created through a substantial expenditure of energy; many potential policy directions are proposed as ideas seeking an agenda with political institutions, but most of these ideas do not actually develop into full-fledged policy products (Howlett \& Ramesh, 1995). Those who internalize this observation posit that most change to existing policy will be incremental in nature, simply adding on to existing policy structures (Birkland, 2010). The clearest example of this kind of understanding comes from existing policy instruments that are implemented through the process of legislation. Rather than repealing an entire statutory scheme, the statutory law is simply amended through subsequent legislation. Over time, amendments provide small changes to the existing structure of the original policy, sometimes changing it substantially through the cumulative impact of numerous amendments over time. This kind of 'policy evolution' is often observed, especially in the United States regarding environmental issues (Percival, 1997).

Others who follow policy development and change have noticed that policy evolution is not always as linear as incremental theory suggests. Sometimes policy change happens rapidly (Brock, 2006), showing entirely new directions that are unrelated to previous policy directions (Baumgartner, 2006). Sometimes these new directions occur from 'scratch,' meaning they derive from no previous policy framework. Other times these new policy directions deviate drastically from preexisting frameworks (Baumgartner, 2010). While the reasons for these differences are not well understood, the observation of their existence questions some of the underlying foundations of policy development and change described by the incremental theory identified above.

The fact is evidence exists to support policy evolution that fits both an incremental and non-incremental explanation. Those who study environmental issues should be aware of both options while paying particular attention to the kind of process that may be suited to the environmental issue under consideration. I propose in this article that many environmental issues would benefit from a non-incremental or 'fresh start' approach to policy development. This theory is based on the following factors I see as consistent with environmental policy development: (1) most environmental issues are complex and not well understood; (2) most 
environmental policy is reliant on scientific expertise; (3) scientific expertise is a reductive process, meaning science refines our understanding of an environmental issue over time; and (4) preexisting policy structures often create unnecessary limitations that prevent the full implementation of scientific information thereby limiting the effectiveness of the policy instrument.

What is not being discussed in this article are the political dynamics that precede policy legitimization and implementation, which tend to dominate the early states of policy development. These political issues have been well studied and are generally accepted as dynamics of the democratic political system (Dye, 2008). The focus here is on structural issues of policy development outside of this political process; specifically, is it better to deal with incremental structures of policy development or it is better to start from scratch when conditions are appropriate? In order to begin a discussion on this question, we must first determine under what conditions an environmental issue might be 'ripe' for entirely new policy directions, i.e., moving away from incremental mechanisms. I do not purport to identify all circumstances in which new policy directions might be applicable in this article. However, a case study of fishery management is used here as an example to highlight several issues that are relevant for consideration. Prior to engaging in a case study analysis, a quick discussion about how science and policy tend to overlap in theoretical function is discussed, the purpose being to identify how this theory may contradict traditional notions of scientific research. Since scientists are important contributors to meaningful policy development in the environmental arena, some additional light should be shed on the process of science development versus policy development, at least in terms of how different approaches can compliment one another to a shared goal.

\section{Differences in How Science and Policy Evolve}

In many respects science has evolved to areas of high specialization, with members of the academy sharing little expertise between disciplines. However, all members of the scientific community share a common heritage and understanding, one that is founded on the principles of the scientific method. These principles are, as stated above, based on a premise that science reduces uncertainty by a process of inquiry and rigorous testing. The hallmark of this rigor is replication, the ability of the findings to be replicated by others. By definition this kind of process relies on previous work; the previous work becomes the very foundation of future work. In other words, science is built upon what has come before. Peer review ensures the validity of what is being suggested today, and if sufficiently replicable and meaningful, the findings of today add to the knowledge base for tomorrow. This approach to knowledge is the very definition of incremental evolution, adding on to what has come before.

I have found an interesting corollary to the scientific method process-wise in Charles Darwin's Theory of Evolution by Natural Selection. As proposed by Darwin and supported over time through experiments using the scientific method, natural selection holds that evolution is incrementally built off of what has come before. Our existence is due to a process by which genetic traits evolve to adapt to stimuli, the end result being a long shared ancestry between all living things today to the first instance of life on Earth at the molecular 
level. It is fascinating, and provides an important role in our true understanding of who we are and where we come from. Science is a discipline that embraces this understanding of the incremental nature of life, looking to add to the story through studies that confirm and sometimes further this understanding.

Policy is really a process that tries to provide the 'best' fit between public goals and what we might currently know about how to achieve those goals. While policy is often informed by what has come before, there is no requirement that policy must be built from previous structures. Rather, policies can be developed anew, often disregarding many - or all - of the precepts that defined previous policy directions. The suggestion here is public policy has the ability to - and often should - revisit a current policy issue with completely new approaches, not being bound by preexisting structures or frameworks. This is, I argue, especially true in the context of today's environmental problems.

Most of the difficult environmental problems today involve a mix of dynamic factors and transitory governance structures. Atop of this is a developing body of science (aided by technological advances) that is rapidly changing the knowledge base upon which environmental policy decisions depend. Existing policy structures often impede meaningful integration of this information for a variety of reasons. For example, institutional actors develop an understanding of existing frameworks and use this understanding to engage in strategies that 'game' the system in their favor. Changes in policy landscape frustrate the capacity of such actors to employ their strategies; in some ways this is like changing the rules to the game of Chess in order to limit those who wish to take advantage of already learned strategies. In addition, actors with strategies in an existing policy setting can collectively incapacitate the policy framework to adapt to changes outside the policy framework. This includes changes like new scientific information being accepted into the policy environment, or the acceptance of different frameworks that might be more adaptable to addressing the underlying policy problem. What follows now is an example of existing policy structure that exhibits some of the tensions described above.

\section{United States Fishery Management: Structural Issues in the Existing Framework}

United States federal fisheries management has existed under its current structural form since the 1970s. The basic management structure flows from a federal law passed by Congress generally referred to as the Magnuson-Stevens Fishery Conservation and Management Act (MSA). There have been amendments to this federal law that have added elements to the original policy framework, most notably a focus on sustainable fishery goals in 1996 and a more rigorous set of goals to end overfishing in the late 2000s. However, the original policy framework of this federal law remains intact, and we begin our discussion focused on this framework.

The general policy framework of the MSA provides a distributive decision-making model of governance. Stakeholders from various backgrounds, both public and private, select representatives to oversee the process of determining how best to determine the amount of target fish species that can be taken in a given season, and also how to allocate this amount amongst fishers. Interests within this stakeholder council setting vary from those who fish the 
resource to those who wish to prevent fishing of the resource. Politics plays a role in the process as well, where elected officials are given appointment authority over some of the representatives within the council setting. There are other groups outside the council, both public and private, that influence the final decisions made about how the fish resource is measured and then allocated. While the details of the process are beyond the purpose of this article due to space limitations, it is enough to know the process is highly convoluted.

One part of the process that is important to understand is the role science plays in helping to make decisions about how much of any target fish species can be taken in a given season generally referred to as 'catch limits.' The policy directive under the MSA mandates that decisions about establishing catch limits be based on the best scientific information available. And this brings us to the heart of the critique for this example, specifically, does the system allow for the 'best' science to dictate the policy decisions being made? There is evidence the current system has what we will call 'structural defects' that limit the ability of new scientific information to be internalized in decision-making. The reasons for wanting to limit the use of science in making these decisions are varied, but they all share the common use of existing structures and rules to limit the impact of science on the final decision-making process. What follows is an explanation of how these existing structures can result in some of the defects outlined above.

The structural issues that can arise from the attempt to add new policy directives into existing policy structures, specifically within U.S. fishery policy, have been previously detailed in the literature (McGuire \& Harris, 2010). The analysis was focused on what is termed 'back-ended' issues in U.S. fishery policy. Specifically identified are existing policy frameworks that provide opportunities to limit the use of scientific information. Because the frameworks exist in both executive and judicial branches of government activity, it is most likely those who have knowledge of the various dynamics of the extended policy framework would be most capable of taking advantage of these system components to, for example, limit how new scientific information is absorbed into the decision-making process. A more detailed explanation of these several policy structures follows.

The goal of the McGuire and Harris (2010) article is to identify some of the 'drivers' impacting how decisions are made in U.S. fishery policy at the federal level. In focusing on the structure of the existing policy environment a few key factors were identified that had the potential to impact fishery policy decisions, including how science is used in decision-making. The first factor was the competing statutory goals of two federal laws impacting fishery management; the fishery law MSA, which has a stated goal of using the 'best available science' to maximize fishing yield while sustaining the fishery; and the National Environmental Policy Act (NEPA), which focuses on ensuring environmental impacts are considered as part of the quota setting process.

The other factor found to have potential to impact fishery management policy was the role of judicial review in fishery management decisions. Based on current interpretation of case law, a deferential standard of review is applied by the federal court system when the court is deemed to be reviewing an agency decision that is within the discretion given to that agency 
through congressional enactment. So, for example, if the MSA indicates agencies are to base their decisions in setting quotas on the 'best available science,' then so long as the agency puts forward an intelligible statement that scientific information was considered in the review process, including evidence new scientific information was made part of the administrative record during review, courts will defer to the 'agency expertise' and not second guess the manner in which the agency made the decision.

The way in which these two factors can impact policy directions are varied, but here now is offered a few comments on how these existing structures can prevent, for example, the influence the use of science as a driver of fishery management decisions.

Consider new scientific information that is directly relevant to stock assessment of a target fish species, and thereby also relevant to the quota that might be established by a fishery management council in conjunction with NOAA Fishery oversight and approval. If we try and follow how this information is handled (for an understanding of how information can be followed in a policy-related decision-making process, see McGuire (2011)) we can identify some of the potential barriers by noting places within the review process that can limit the full consideration of this information. For example, current MSA structure would allow for the gathering of relevant information by subcommittees charged with handling different policy goals related to its statutory mandate: biomass calculations, essential habitat identification, etc. This information would likely be queued into the administrative record, meaning it would be accepted but not necessarily reviewed in a meaningful way. Why not? The environmental impact statute, NEPA, provides incentives for information to be queued into the system but not actually dealt with early in the process because by doing so an agency may confront information that hampers their ability to defend against a particular quota decision; the main driver here being time constraints.

Consider that decisions about total allowable catch must be made on a regular basis, usually annually. The current system is entirely 'front-loaded' with information that forms of the basis of this decision-making, including assumptions premised on the validity of existing scientific information. If new scientific information becomes available that might impact the relied upon assumptions, then there is a limited capacity to acknowledge this new information, even if that capacity is based on time constraints. Better for the organization to hold onto that information but not meaningfully interpret that information. The reason why is because there is generally limited capacity to alter the current quota directions. Moreover, there is little incentive to do so. Under a doctrine of judicial deference, agencies have a stronger defensive posture in litigation when they can defend their ultimate decision by indicating all scientific information has been allowed into the review process, thereby concluding the decision is made based on the best scientific information available - even where information is disregarded in the final decision. This makes practical sense when the current policy environment focuses on ensuring a process of information flow and not necessarily information review. The mix of fast and recurring deadlines in setting quotas under MSA and the administrative review procedures under NEPA incentive a kind of defensive posture where radically new information can easily be seen as a negative by the policy actors when making decisions. Institutional knowledge allows for the development of 'defensive' tactics 
towards innovation, and the diminished form of judicial review provides little incentive to invite new information that might impact the normalized process undertaken by public institutions in their recognized settings.

\section{Discussion}

The fishery management example above is admittedly brief and only discusses a few aspects of how existing policy structures can impact the ability of institutions to meaningfully adapt to new information. Many times in environmental issues scientists and advocates wonder why new information takes so long to be absorbed by the public institution. This is of special concern when we consider the potential impacts of exponential forces in environmental problems because such forces can begin to show symptoms when there is little time to respond. Environmental threats that are dynamic in nature require policy frameworks that are adaptable and responsive to the best forms of information available. One way to encourage the development of such policy frameworks is to differentiate between scenarios where incremental policy is distinguished from the need to move quickly in new policy directions.

There are strong disincentives for actors within public policy institutions to abandon previous policy directions in favor of entirely new directions. Previous policy frameworks are well understood by actors; most if not all of the institutional knowledge related to those previous frameworks are lost when new policy directions are taken. In addition, there is the assurance that what has been done previously has not been totally detrimental; less is known about moving into policy frameworks with no history and therefore little capacity to judge the merits of the new direction. Still, this argument might be of little value when we consider a variety of environmental issues that are priorities today. Climate change, resource scarcity, and other major environmental issues seem to benefit little from adding to previous policy frameworks. Indeed, many of these frameworks were never developed to adequately address fast-changing circumstances, so why should one believe that framework would be responsive to new issues? More likely, new issues need new solutions, including reliance on the best science and technology has to offer to assist our assessment, response, and evaluation of environmental problems. If it is advisable to develop wholly new policy frameworks to support the best information available, then we should feel empowered to develop such structures without feeling bound to what has come before.

\section{References}

Baumgartner, F. (2006). Punctuated equilibrium theory and environmental policy. In R. Repetto (Ed.), Punctuated equilibrium and the dynamics of U.S. environmental policy (pp. 24-46). New Haven: Yale University Press.

Birkland, T. (2010). An introduction to the policy process: theories, concepts, and models of public policy making. ( $3^{\text {rd }}$ ed.). New York: M.E. Sharpe.

Brock, W. (2006). Tipping points, abrupt opinion changes, and punctuated policy change. In R. Repetto (Ed.), Punctuated equilibrium and the dynamics of U.S. environmental policy (pp. 47-77). New Haven: Yale University Press. 


\section{Macrothink}

Dye, T. (2011). Understanding public policy. $\left(13^{\text {th }}\right.$ ed.). New York: Pearson.

Howlett, M. \& Ramesh, M. (1995). Studying public policy: policy cycles and policy subsystems. New York: Oxford University Press. p.104-121.

Lindblom, C. (1959). The science of “muddling through.” Public Administration Review, 19(2), 79-88. http://dx.doi.org/10.2307/973677

McGuire, C. \& Harris, B. (2010). Some back-ended legal and political issues in United States fisheries management. Journal of Politics and Law. 3(2), 52-62.

McGuire, C. (2011). A framework for analyzing information flows in public policy decision-making: a move towards building sustainable policy instruments. Journal of Politics and Law. 4(2), 25-35. http://dx.doi.org/10.5539/jpl.v4n2p25

Percival R (1997) Regulatory evolution and the future of environmental policy. The University of Chicago Legal Forum. 159.

\section{Copyright Disclaimer}

Copyright reserved by the author(s).

This article is an open-access article distributed under the terms and conditions of the Creative Commons Attribution license (http://creativecommons.org/licenses/by/3.0/). 